Session 2425

\title{
A 6-Hats Based Team Formation Strategy: Development and Comparison with an MBTI Based Approach
}

\author{
Dan Jensen, John Feland, Martin Bowe and Brian Self \\ Dept. of Engineering Mechanics \\ United States Air Force Academy \\ USAF Academy, CO 80840
}

\section{Abstract}

Although various strategies for forming design teams have been documented in the literature, there continues to be a need to assess these established strategies as well as to propose new ones. In the present study the development of a new team formation strategy based on the "Six Thinking Hats" of Edward DeBono is described. An instrument for categorizing students according to their "Six Hats" preference for group interaction as well as the strategy for using this data to form design teams is presented. In order to determine the validity of this 6-Hats categorization instrument, the students provided feedback on the accuracy of their " 6 -Hats" preference for group interaction. This information indicates that the instrument used to assign a 6-Hats communication style works well; with $84 \%$ of the students reinforcing that their 6-Hats "type" is indeed one of their preferred styles of group communication. To further assess the 6Hats method of design team formation, teams formed using this new method are compared with teams formed using a Myers Briggs based formation technique. As the two different team formation techniques have slightly different goals, this assessment incorporates both sets of goals as well as some generic measures of design team effectiveness. The results indicate that the teams formed using the 6-Hats based strategy more completely meet the 6-Hats goals than do the non-6-Hats based teams. Similarly, the MBTI based teams meet the MBTI based goals better than do the non-MBTI based teams. Also of interest is the fact that the teams which meet both the 6-Hats and the MBTI criteria for team formation report increased effectiveness in every category when compared with teams who meet either the 6-Hats or the MBTI criteria, but not both. More data is required to provide definitive, statistically significant results (this data is currently being taken), but the initial results indicate that this new team formation strategy has significant promise.

\section{Overview}

Various researchers [Wilde 1993, 1997, 1999, Trevistan 1998, 1999] have investigated different techniques for forming and assessing design teams. Although progress has been made in both the formation and assessment areas, there are still significant questions to be answered. The present work presents a new approach in both design team formation and the assessment of these 
teams. This work was done at the United States Air Force Academy in the fall semester of 1999 using two sections (about 50 students) of the sophomore level mechanical design class. Further data is being gathered in an additional eight sections (about 200 students) of a freshman/sophomore level Introduction to Mechanics course. Specifically, a new design team formation strategy (TFS) based on the work of DeBono [DeBono 1985] called the "6 Thinking Hats" has been developed. In addition, an assessment strategy has been developed which compares the new 6-Hats TFS to a Myers Briggs Type Indicator (MBTI) based TFS.

The 6-Hats work of DeBono describes six ways of thinking/interacting. DeBono's primary thrust in his work was to provide ways to enhance communication by identification of these different communication styles or roles with the idea that, once a style/role is identified, it becomes easier to switch into that style/role when needed. The new 6-Hats based TFS, which is the focus of this paper, takes the 6 different styles/roles identified by DeBono and uses them in a completely different manner. Specifically, the 6-Hats based TFS has two parts. Initially it uses a 30 question survey to rank the student's preference for using each of the six communication styles/roles. This preference order is referred to as the student's 6-Hats "type" in much the same way as a student has a Myers Briggs "type". Secondly, the 6-Hats based TFS uses each student's 6-Hats type to form design teams using a simple algorithm. This algorithm is based on the 6Hats TFS goals as seen in Table 1 below. The details of this process are given below in the Section II: 6-Hats Based Team Formation.

In much the same way, students in this study were given a form of the MBTI test. To this end, the Keirsey instrument was used [Keirsey 1984,1999]). As with the 6-Hats TFS, the MBTI types were used in accordance with a simple algorithm to form MBTI based design teams. This algorithm is based on the MBTI TFS goals as seen in Table 1 below. Details of this process are given below in Section III: MBTI Based Team Formation.

Table 1 - Goals of the 6-Hats and MBTI TFS

\begin{tabular}{|l|l|}
\hline \multicolumn{1}{|c|}{ TFS } & \multicolumn{1}{c|}{ Goal } \\
\hline 6-Hats & Provide creativity \\
\cline { 2 - 2 } & Provide mixed positive and negative feedback \\
\cline { 2 - 2 } & Provide team leadership \\
\hline \multirow{2}{*}{ MBTI } & Provide creativity \\
\cline { 2 - 2 } & Provide mixed quick and extended decision making \\
\cline { 2 - 2 } & Provide mixed logical and intuitive thinking \\
\hline
\end{tabular}

Two types of assessment were accomplished in this present work. First, in order to verify that the survey utilized to derive a student's 6-Hats type is accurate, an instrument was used to obtain feedback from each student by directly asking them to rank which of the 6 styles/roles they use the most when interacting with their team. Secondly, an instrument was developed to gage team effectiveness in a number of specific ways. This instrument was used both on 6-Hats based 
teams and MBTI based teams. The goal here was obviously to determine if one TFS provided superior team effectiveness. Results are correlated with the specific TFS goals shown in Table 1. The results of these assessments as well as additional details regarding the assessment instruments themselves can be found in Section IV: Results.

\section{6-Hats Based Team Formation \\ II.1 Overview of the 6 Hats Concept}

As previously mentioned, the original 6-Hats work of DeBono [DeBono 1985] had a different focus than this current work. In the original work, six communication styles/roles were identified. Each style/role was identified by a certain color. When a person was using that particular style/role, they were said to be wearing that "hat". The six styles/roles are summarized in the Table 2.

In the original 6-Hats work, there were five purposes for identifying these 6 communication styles/roles: 1) Helps in role playing, 2) Helps focus attention on seeing things from a new angle, 3) Provides an easy way to ask someone to switch gears and think a different way, 4) Using the 6 hats may help develop new neural patterns in your brain (thus making it easier to think in different manners than you were previously used to) and 5) Can be used to establish "rules of the game" for brainstorming. The current work focuses on the use of these 6 styles/roles in a different manner. The idea in this present work is simply that each individual has established patterns of communication which can be identified using the 6-Hats categories. Once these preferred communication styles/roles are identified, they may be used in a design team formulation strategy (TFS) to both balance communication styles/roles as well as to ensure certain styles/roles are present. In order to accomplish this, two tools needed to be developed: 1) an instrument to identify a person's preferred communication styles/roles within the 6-Hats framework (called their 6-Hats "type") and 2) an algorithm to use this data to form design teams. Together these two tools constitute the 6-Hats TFS. 
Table 2: Overview of 6-Hats Communication Styles/Roles

\begin{tabular}{|c|c|}
\hline $\begin{array}{l}\text { White Hat } \\
\text { - I focus on objective facts. } \\
\text { - I enter into a discussion without preconceived } \\
\text { ideas on a solution } \\
\text { - I seek to know that facts of a situation } \\
\text { - I seek to know the statistical evidence } \\
\text { concerning a decision } \\
\text { - I try to think totally objectively about a } \\
\text { situation } \\
\text { - I seek to differentiate between facts and } \\
\text { - I } \text { I aminions more interested in facts than opinions }\end{array}$ & $\begin{array}{l}\text { Red Hat } \\
\text { - } \quad \text { My feelings sway my decisions } \\
\text { - I have good intuition } \\
\text { - I often have hunches about the best decision } \\
\text { - My personal opinions play a significant role in } \\
\text { my decision making process } \\
\text { - I listen to my emotions when making decisions } \\
\text { - } \text { mam suspicious of other people's decision } \\
\text { - I think emocess } \\
\text { decision making }\end{array}$ \\
\hline $\begin{array}{l}\text { Yellow Hat } \\
\text { - I usually see the positive side of things } \\
\text { - I can often see the good parts of even a bad idea } \\
\text { - I am usually optimistic that a new idea will } \\
\text { work } \\
\text { - I tend to see the valuable contributions in } \\
\text { people's ideas } \\
\text { - I believe that most new ideas have significant } \\
\text { value } \\
\text { - I usually "look on the bright side" of a problem } \\
\text { My comments are usually positive and } \\
\text { constructive }\end{array}$ & $\begin{array}{l}\text { Black Hat } \\
\text { - I can quickly see why an idea will not work } \\
\text { - I often can tell an idea will not work by judging } \\
\text { from past experience } \\
\text { - I like to play the "devil's advocate" } \\
\text { - I can usually see the pitfalls in an idea } \\
\text { - I can readily detect poor logic in someone's } \\
\text { - } \quad \text { I find it easy to be critical of other's ideas } \\
\text { - I am often pessimistic of others ideas }\end{array}$ \\
\hline $\begin{array}{l}\text { Green Hat } \\
\text { - I am creative } \\
\text { - I often generate new ways of thinking about a } \\
\text { problem } \\
\text { - I easily think "outside of the box" } \\
\text { I am good at finding new approaches to solving } \\
\text { a problem } \\
\text { - I am constantly thinking of alternatives } \\
\text { - I am not likely to settle for the "status quo" } \\
\text { I can easily generate new concepts }\end{array}$ & $\begin{array}{l}\text { Blue Hat } \\
\text { - I like to lead the problem solving process } \\
\text { - I tend to think as much about the problem solving } \\
\text { process as the problem itself } \\
\text { - I focus on the big picture, summarize and draw } \\
\text { conclusions } \\
\text { - I find myself trying to keep the group focused } \\
\text { - I tend to try to optimize the group problem } \\
\text { - } \quad \text { solving process } \\
\text { - I often help the group clearly define the problem } \\
\end{array}$ \\
\hline
\end{tabular}

\section{II.2 The 6-Hats Based Team Formation Strategy (TFS)}

The first tool in the 6-Hats TFS is the 6-Hats "typing" instrument which is used to determine a person's relative preference for each of the 6 styles/roles designated in the previous section (i.e. find their 6-Hats "type"). The instrument used to determine a person's 6-Hats type is shown in Appendix I. It is written in Microsoft Excel and contains 30 questions. The instrument is emailed as an attachment to each student in the course(s). Students email back the completed instrument. A separate Excel spreadsheet is used to score the instruments. Of the 30 questions on the instrument, 5 are dedicated to each of the 6-Hats types. These 5 questions attempt to ascertain the student's preference for functioning within that particular 6-Hats style/role. The 
students' numerical answers on these 5 questions therefore indicate his/her preference for that style/role. The scoring spreadsheet computes an average and standard deviation over the full 30 questions and then computes the average of the 5 questions pertaining to each of the 6 styles/roles as individual entities. This data is easily manipulated to produce the number of standard deviations above or below the mean for each of the 6 styles/role for each student. The resulting 6 numbers that represent the student's preference for interacting using these 6 styles/role constitute that student's 6-Hats "type". Both the 6-Hats instrument and the scorer spreadsheet are available by simply emailing the primary author at dan.jensen@usafa.af.mil.

Once each student has been designated a 6-Hats type (consisting of the 6 numbers derived as described above), that data is used to place students on teams. The algorithm for doing this has four simple steps as shown below in Figure 1. The criteria in all four steps must be met for a team to be designated a "6-Hats Team" (i.e. a team formulated using the 6-Hats TFS).

1. Place a student on the team who has "Green" as their primary 6-Hats type

2. Place a student on the team who has "Yellow" as their primary 6-Hats type

3. Place a student on the team who has "Black" as their primary 6-Hats type

4. Place a student on the team who has "Blue" as at least their second 6-Hats type

Figure 1 - 6-Hats TFS Algorithm

The rational behind this particular algorithm can be seen by considering the specifics on the green, yellow, black and blue styles/roles as shown in Table 2. The green style/role represents creativity. This is obviously a critical style/role for someone on the team to posses. Therefore, the first criteria in the 6-Hats TFS algorithm is a predominately "Green-Hat" member. As can be seen in Table 2, the yellow and black style/roles represent opposite methods for providing feedback on new ideas. The yellow style/role provides positive feedback and encouragement to proceed with an idea while the black style/role provides constructive criticism and adds needed realism to potential ideas. This justifies the number 2 and 3 criteria. Finally, the blue style/role represents the leadership functions needed in a design team. Big picture perspective and overall problem definition are parts of this style/role. This motivates the fourth criteria in the 6-Hats TFS algorithm. Note that the red and white style/roles are not used in the 6-Hats algorithm. Although it would be preferable to have a mix of red and white style/roles on a team, due to the team size being 4 members, it becomes increasingly difficult to satisfy additional criteria.

III. MBTI Based Team Formation

\section{III.1 Overview of the MBTI concept}

Use of the Myers Briggs Type Indicator (MBTI) data for purposes of improving engineering courses has been investigated by various researchers including the current author [Jensen 1998, 1999, Borchert 1999, Wilde 1999, 1997, 1993]. McCaulley et. al. in conjunction with the Center 
for Applied Psychological Type have determined MBTI type for thousands of engineering students at various universities. This data has been analyzed for application to student learning as well as for possible use in career counseling and student retention strategies [McCaulley 1990, 1983, 1976]. Other examples include using MBTI to develop self instruction materials [Smith 1973], using MBTI comparisons between freshman and senior students to determine the change in preference brought about during the four years of engineering curriculum [Rodman 1986] and work which has shown the potential to increase academic success of struggling students by strengthening their non-preferred areas [Rosati 1993].

The present work uses what is known from MBTI type preferences and their affects on group communication in order to guide continuing improvements in design team formation. The MBTI type includes four categories of preference [Myers1985, Jung 1971, Keirsey 1984, 1999]. The four letter combination of these indicators ("E" vs. "I" for extrovert and introvert; "S" vs. "N" for sensor and intuitor; "T" vs. "F" for thinker and feeler; "J" vs. "P" for judger and perceiver) constitute a person's MBTI "type". Table 3, which is adapted from Manual: the Myers-Briggs Type Indicator [Myers, McCaully 1976], gives a brief overview of the four MBTI categories.

Table 3 - Overview of the MBTI Categories

\begin{tabular}{|c|c|c|c|}
\hline \multicolumn{4}{|c|}{ Manner in Which a Person Interacts With Others } \\
\hline $\mathbf{E}$ & $\begin{array}{l}\text { Focuses outwardly on } \\
\text { others. Gains energy } \\
\text { from others. }\end{array}$ & $\begin{array}{l}\text { Focuses inwardly. Gains } \\
\text { energy from ideas and } \\
\text { concepts. }\end{array}$ & $\mathbf{I}$ \\
\hline \multicolumn{2}{|c|}{ EXTROVERSION } & \multicolumn{2}{|c|}{ INTROVERSION } \\
\hline \multicolumn{4}{|c|}{ Manner in Which a Person Processes Information } \\
\hline $\mathbf{S}$ & $\begin{array}{c}\text { Focus is on the five } \\
\text { senses and experience. }\end{array}$ & $\begin{array}{l}\text { Focus is on possibilities, } \\
\text { future use, big picture. }\end{array}$ & $\mathbf{N}$ \\
\hline \multicolumn{2}{|c|}{ SENSING } & \multicolumn{2}{|c|}{ INTUITION } \\
\hline \multicolumn{4}{|c|}{ Manner in Which a Person Evaluates Information } \\
\hline $\mathbf{T}$ & $\begin{array}{l}\text { Focuses on objective } \\
\text { facts and causes \& } \\
\text { effect. }\end{array}$ & $\begin{array}{l}\text { Focuses on subjective } \\
\text { meaning and values. }\end{array}$ & $\mathbf{F}$ \\
\hline \multicolumn{2}{|c|}{ THINKING } & \multicolumn{2}{|l|}{ FEELING } \\
\hline \multicolumn{4}{|c|}{ Manner in Which a Person Comes to Conclusions } \\
\hline $\mathbf{J}$ & $\begin{array}{l}\text { Focus is on timely, } \\
\text { planned conclusions } \\
\text { and decisions. }\end{array}$ & $\begin{array}{l}\text { Focus is on adaptive } \\
\text { process of decision } \\
\text { making. }\end{array}$ & $\mathbf{P}$ \\
\hline \multicolumn{2}{|c|}{ JUDGEMENT } & \multicolumn{2}{|c|}{ PERCEPTION } \\
\hline
\end{tabular}




\section{III.2 The MBTI Based Team Formation Strategy (TFS)}

As with the 6-Hats based TFS, the process of forming teams using the MBTI based approach has two basic steps: 1) Determination of the MBTI type and 2) Use of the MBTI type in an algorithm to form the teams. In the first step, each student's MBTI type must be determined. In order to accomplish this, the web based version of the Keirsey instrument has been used in this study. This instrument can be found at http://www.keirsey.com . There are two different tests on this site. The 36 question test "Keirsey Temperament Sorter" has been used for this work. In addition, this site scores the test and has a wealth of background resources.

Once the students' MBTI types are determined, an algorithm is used to form the teams. Five specific criteria make up the MBTI team formation algorithm as shown in figure 2. All five of these criteria must be met for a team to be categorized as an MBTI-based team. Refer to Table 3 for explanations of the MBTI categories.

1. Either put an "Extroverted Intuitor (EN)" on the team or as a secondary option, put an "Introverted Intuitor (IN)" on the team and assure that someone else on the team is an "Extrovert".

2. Make sure there is a "Judger (J)" on the team.

3. Make sure there is a "Perceiver (P)" on the team.

4. Make sure there is a "Thinker (T)" on the team.

5. Make sure there is an "Feeler (F)" on the team.

Figure 2 - MBTI TFS Algorithm

The logic behind these five criteria can be seen by referring to the description of the MBTI categories in Table 3 above. Criteria 1 attempts to ensure that the simplest MBTI version of a "creative" person ("Intuitor") ends up on the team and that their creative ideas are expressed ("Extrovert"). Note that the literature contains detailed work done to correlate MBTI and creativity [Thorne] and, in that light, criteria 1's description of creativity is extremely basic. The mix of criteria 2 and 3 attempts to ensure that the team will be mixed between those who are ready to make decisions on limited data ("Judger") and those who want to fully consider ALL the options before making a decision ("Perceiver"). Criteria 4 and 5 are designed to create a mix between those who make decisions by concentrating on facts and logical relationships ("Thinker") and those who allow insight and intuition to play significant roles ("Feeler").

\section{Results}

The results for the present work have two separate goals. The first goal is to validate the 6-Hats typing instrument itself. This is done through a survey given to the students which simply asked students which 6-Hats category best describes their dominant style/role on their team. The results of this survey are shown in the next section. The second goal of the assessment process is 
to measure the effectiveness of the 6-Hats and MBTI based design teams. These results are shown in section IV.2 below.

\section{IV.1 Assessment of the 6-Hats instrument}

As mentioned above, the first goal of the assessment process is to validate the newly created 6Hats typing instrument. This instrument (See Appendix 1) was created through a detailed review of the original 6-Hats work of DeBono [DeBono 1985]. Key characteristics of each of the 6 styles/roles were identified. These characteristics were used to form the 30 items on the instrument. Each of the 6 styles/roles is directly correlated to 5 specific items on the instrument. For example, the first two items on the instrument state 1) "Focus on objective facts" and 2) "Have my feelings sway my decisions". These are critical parts of the "White" and "Red" hat style/roles respectively. The other 28 questions are similarly correlated with the various 6 styles/roles.

In order to validate this instrument as a reliable way to assign a student a 6-Hats "type", an additional survey instrument was developed which requests information from the students pertaining to the style/roles they prefer to use when working in their groups. This validation instrument is shown in Appendix III. On close inspection, it can be seen that there is a close association between the typing instrument in Appendix I and the validation instrument in Appendix III. This is by design. In contrast to the original typing instrument, the validation instrument has the complete list of characteristics of each 6-Hats style/role in a single list.

At the beginning of the course, the students each completed the original typing instrument. Toward the end of the course the students completed the validation instrument. Note that the algorithm used to assign students to groups (see figure 1) uses only the student's most dominant 6-Hats style/role for fulfilling criteria 1-3 and then uses the student's most dominant and second most dominant style/role for the fourth criteria. Therefore, the primary question pertaining to validation is whether the dominant style/role, as described by the original typing instrument, is identified by the validation instrument as a truly dominant style/role. Correlation between the original typing instrument and the validation instrument shows that the style/role identified by the original typing instrument as dominant for that particular student was later rated, in the validation instrument, as one of their preferred style/roles $84 \%$ (see Table 4) of the time. This indicates that the original typing instrument does a reasonable job of correctly identifying the students' preferred style/roles of interacting with their groups. The details of these results are shown below in Table 4. Notice from Table 4 that the percentage of students selecting the exact same style/role in the validation instrument as was identified in the original typing instrument was $42 \%$. The percentage of those whose selected $2^{\text {nd }}$ or $3^{\text {rd }}$ dominant style/role was identified as their primary style/role in the original typing instrument was $23 \%$ and $19 \%$ respectively. This means that those who whose selected $4^{\text {th }}, 5^{\text {th }}$ or $6^{\text {th }}$ style/role was identified as their primary style/role in the original typing instrument was only $16 \%$. 
Table 3

Statistical Correlation Between the Original Typing \& Validation Instruments

\begin{tabular}{|c|c|c|c|}
\hline $\begin{array}{c}\text { Ranking According } \\
\text { to Original Type } \\
\text { Survey }\end{array}$ & $\begin{array}{c}\text { Ranking According } \\
\text { to Validation } \\
\text { Survey }\end{array}$ & $\begin{array}{c}\text { Percentage of Time } \\
\text { This Correlation is } \\
\text { True (cumulative) }\end{array}$ & $\begin{array}{c}\text { Cumulative } \\
\text { Percentage }\end{array}$ \\
\hline $\mathbf{1}^{\text {st }}$ & $\mathbf{1}^{\text {st }}$ & $\mathbf{4 2 \%}$ & $\mathbf{4 2 \%}$ \\
\hline $\mathbf{1}^{\text {st }}$ & $\mathbf{2}^{\text {nd }}$ & $\mathbf{2 3 \%}$ & $\mathbf{6 5 \%}$ \\
\hline $\mathbf{1}^{\text {st }}$ & $\mathbf{3}^{\text {rd }}$ & $\mathbf{1 9 \%}$ & $\mathbf{8 4 \%}$ \\
\hline $\mathbf{1}^{\text {st }}$ & $\mathbf{4}^{\text {th }}-\mathbf{6}^{\text {th }}$ & $\mathbf{1 6 \%}$ & $\mathbf{1 0 0 \%}$ \\
\hline
\end{tabular}

Another way to view this data is to compute the mean and standard deviation of each student's rankings from the original typing instrument. From this data, for each of the 6 styles/roles the number of standard deviations above/below the mean can be computed. These numbers (called "style/role strengths" below) provide a measure of the strength of each style/role for each person. A secondary mean and standard deviation can be computed across these 6 "styles/roles strengths" for each person. By definition, the mean of these "style/role strengths" must be zero. In order to use this data to measure the validity of the original typing instrument, the style/role selected as primary in the validation instrument is correlated with its corresponding "style/role strength" to determine its number of standard deviations above the secondary mean (of zero). Once this has been computed for each student, a percentile can be obtained from Gaussian distribution. The computed percentile is $78 \%$. This is the percentile correlation between the primary style/role as selected in the validation instrument and the respective "style/role strength" as computed from the original typing instrument.

\section{IV.2 Assessment of the Two Different TFS}

The second goal of the assessment process is to measure the effectiveness of the 6-Hats and MBTI based design teams. In order to accomplish this, the instrument called the Team Effectiveness Survey shown in Appendix II is used. Of the 15 questions on the instrument, 5 of them relate to goals specified in the 6-Hats TFS; 6 relate to goals specified in the MBTI TFS and 6 are general questions relating to team effectiveness. Note that 2 questions specifically relate to goals of BOTH the 6-Hats and MBTI TFS. Question 1, 3, 6, 9 and 15 measure goals of the 6Hats TFS. Questions 1, 7, 8, 10, 11 and 15 measure goals of the MBTI TFS and 2, 4, 5, 12, 13 and 14 measure general team effectiveness issues. This is summarized in Table 5 below. 
Table 5 - Correlation Between TFS, Goals \& Questions on the Team Effectiveness Survey

\begin{tabular}{|c|c|c|c|}
\hline $\begin{array}{l}\text { Statement } \\
\text { Number }\end{array}$ & Statement & TFS & Goal \\
\hline 1 & Our team is very creative & $\begin{array}{l}\text { 6-Hats \& } \\
\text { MBTI }\end{array}$ & Provide creativity \\
\hline 2 & Our team has a lot of conflict & None & General \\
\hline 3 & Our team has a clear leader & 6-Hats & Provide team leadership \\
\hline 4 & Our team is productive and effective & None & General \\
\hline 5 & Our team resolves conflict well & None & General \\
\hline 6 & $\begin{array}{l}\text { Our teams sees the potential in new } \\
\text { ideas }\end{array}$ & 6-Hats & $\begin{array}{l}\text { Provide mixed positive and negative } \\
\text { feedback }\end{array}$ \\
\hline 7 & $\begin{array}{l}\text { Our team approaches problem solving } \\
\text { logically }\end{array}$ & MBTI & $\begin{array}{l}\text { Provide mixed logical and intuitive } \\
\text { thinking }\end{array}$ \\
\hline 8 & Our team procrastinates & MBTI & $\begin{array}{l}\text { Provide mixed quick and extended } \\
\text { decision making }\end{array}$ \\
\hline 9 & $\begin{array}{l}\text { Our team sees when a new idea will } \\
\text { not work }\end{array}$ & 6-Hats & $\begin{array}{l}\text { Provide mixed positive and negative } \\
\text { feedback }\end{array}$ \\
\hline 10 & $\begin{array}{l}\text { Our team uses intuition, hunches and } \\
\text { feeling to aid our problem solving }\end{array}$ & MBTI & $\begin{array}{l}\text { Provide mixed logical and intuitive } \\
\text { thinking }\end{array}$ \\
\hline 11 & $\begin{array}{l}\text { Our team considers the full range of } \\
\text { options before making a decision }\end{array}$ & MBTI & $\begin{array}{l}\text { Provide mixed quick and extended } \\
\text { decision making }\end{array}$ \\
\hline 12 & $\begin{array}{l}\text { Our team's members due their fair } \\
\text { share of the work }\end{array}$ & None & General \\
\hline 13 & I enjoy working on this team & None & General \\
\hline 14 & Our team makes good decisions & None & General \\
\hline 15 & $\begin{array}{l}\text { Our team is good at creating } \\
\text { alternative solutions to problems }\end{array}$ & $\begin{array}{l}\text { 6-Hats \& } \\
\text { MBTI }\end{array}$ & Provide creativity \\
\hline
\end{tabular}

In order to derive overall team effectiveness measures, scores from the individual students on each team are averaged to provide a team-based score for each of the 15 questions. Using these team scores, and noting which questions correlate with which TFS' goals, separate averages can be obtained for each TFS as well as for the "general team effectiveness" category. This is then correlated with which method (6-Hats or MBTI) was used to form the team. The results can be seen in Table 6 . Note that some teams were originally formed using one method but coincidentally met the criteria for both the 6-Hats AND the MBTI TFS. To review the specific criteria for the 6-Hats and MBTI based TFS, see Figures 1 and 2. Also note that the meaning of the numerical values in Table 6 follows from the instructions given in Appendix 2 where it is stated that: $+2=$ Very True; $\quad+1=$ Mostly True; $\quad 0=$ Neutral; $\quad-1=$ Mostly Un-True; $\quad-2=$ Very Un-True. 
Table 6 - Results of Team Effectiveness vs. Team Formation Strategy (TFS)

\begin{tabular}{|c|c|c|c|c|}
\hline TFS description & $\begin{array}{c}\text { Score on 6-Hats } \\
\text { Based Questions }\end{array}$ & $\begin{array}{c}\text { Score on MBTI } \\
\text { Based Questions }\end{array}$ & $\begin{array}{c}\text { Score on General } \\
\text { Questions }\end{array}$ & $\begin{array}{c}\text { Team grade in } \\
\text { this course }\end{array}$ \\
\hline $\begin{array}{c}\text { 6-Hats TFS Criteria } \\
\text { Met }\end{array}$ & 1.11 & 0.90 & 1.13 & 3.14 \\
\hline $\begin{array}{c}\text { 6-Hats TFS Criteria } \\
\text { NOT met }\end{array}$ & 0.84 & 0.62 & 0.88 & 3.09 \\
\hline $\begin{array}{c}\text { MBTI TFS Criteria } \\
\text { met }\end{array}$ & 1.01 & 0.82 & 0.75 & 2.38 \\
\hline $\begin{array}{c}\text { MBTI TFS Criteria } \\
\text { NOT Met }\end{array}$ & 0.98 & 0.71 & 1.29 & 3.27 \\
\hline $\begin{array}{c}\text { BOTH MBTI and 6- } \\
\text { Hat Criteria Met }\end{array}$ & 1.16 & 0.53 & 0.51 & 2.88 \\
\hline $\begin{array}{c}\text { Either MBTI or 6-Hats } \\
\text { Met, but Not Both }\end{array}$ & 0.88 & 1.06 & & \\
\hline
\end{tabular}

A number of observations/conclusions can be made from the data in Table 6. First, it appears that when the 6-Hats TFS criteria are met (compared to when they are not met), the teams rate more highly on both the 6-Hats based questions (1.11 vs. 0.84) as well as the MBTI based questions (0.90 vs. 0.62). For the teams which meet the MBTI TFS criteria (again compared to those who do not met the criteria), the ratings for the MBTI based questions show a significant difference (0.82 vs. 0.71) while the ratings for the 6-Hats based questions do not (1.01 vs. 0.98). Possibly the most significant result (and in all honesty the least expected) appears when teams which meet BOTH criteria are compared with those who met only one of the two criteria. In every category (6-hats based questions, MBTI based questions, general questions and course GPA) the teams which met BOTH sets of criteria rated higher.

\section{Conclusions and Future Work}

In this current work an instrument which provides a new categorization for team interaction styles/roles based on the 6-Hats system [DeBono 1985] was developed. The accuracy of this instrument was measured and was found to be good. Next, the teams formed using the 6-Hats based team formation strategy (TFS) were compared to those formed using a MBTI based TFS. Results show that teams based on the 6-Hats TFS are more effective overall than those based on the MBTI TFS. In addition, those teams which meet both the 6-Hats and the MBTI criteria for team formation were significantly more effective than teams which met only the 6-Hats or the MBTI based TFS criteria, but not both.

The study reported here represents data taken from 2 sections of approximately 25 students each. There were 10 teams, each having 4 or 5 people. A continuation of this work is in progress which will involve about 225 additional students comprising approximately 55 teams. This data will be available for analysis at the end of 1999. It is anticipated that this data will provide statistically significant conclusions where the present data shows only presumably significant (although consistent and predictable) trends. 


\section{Acknowledgments}

The authors wish to acknowledge the support of the Department of Engineering Mechanics at the U.S. Air Force Academy as well as the financial support of the Dean's Assessment Funding Program. In addition support is acknowledged from the Institute for Information and Technology Applications (IITA) at the USAF Academy which funded some of the earlier MBTI work.

\section{References}

1. Borchert, R., , Jensen, D., Yates, D., "Development and Assessment of Hands-on and Visualization Modules for Enhancement of Learning in Mechanics", Proceedings of the ASEE Annual Conference, Charlotte, NC, June, 1999.

2. DeBono, E., Six Hats Thinking, Little, Brown and Co, Boston, MA, 1985.

3. Jensen, D., Bowe, M., "Hands-on Experiences to Enhance Learning of Design: Effectiveness in a Reverse Engineering / Redesign Context When Correlated with MBTI and VARK Types," Proceedings of ASEE Annual Conf., Charlotte, NC, June, 1999.

4. Jensen, D.D., Murphy, M.D., Wood, K.L., "Evaluation and Refinement of a Restructured Introduction to Engineering Design Course Using Student Surveys and MBTI Data,", Proceedings of the ASEE Annual Conference, Seattle WA, June, 1998.

5. Jung, C.G., "Psychological Types," The Collected Works of C.G. Jung, 6, Princeton Univ. Press, 1971 (originally published 1921).

6. Kersey,D., and Bates, M. , Please Understand Me, Prometheus Press, 1984.

7. Keirsey, D., Web site for type development, http://www.keirsey.com, 36 question character sorter test, 1999.

8. McCaulley, M.H., Mary, H., "the MBTI and Individual Pathways in Engineering Design", Engineering Education, Vol. 80, pp. 537-542, July/Aug. 1990.

9. McCaulley, M.H., "Psychological Types in Engineering: Implications for Teaching," Engineering Education, Vol. 66, No. 7, pp. 729-736, April 1976.

10. McCaulley, M.H., et. al., "Applications of Psychological Type in Engineering Education”, Engineering Education, Vol. 73, No. 5, pp. 394-400, Feb. 1983.

11. Myers, I.B., McCauley, M.H., Manuel: A Guide to the Development and Use of Myers Briggs Type Indicator ( $2^{\text {nd }}$ ed.), Palo Alto, CA, Consulting Psychologists Press, 1985.

12. Rodman, S.M. Dean, R.K., and Rosati, P.A., "Self-perception of Engineering Students' Preferred Learning Style Related to MBTI Type", Proceeding of the ASEE Annual Conference, pp.1303-1313, 1986.

13. Rosati, P., Yokomoto, C. F., "Student Attitudes Toward Learning: By Seniority and By Type," ASEE Annual Conference Proceeding, pp. 2038-2043, 1993.

14. Smith, A. B., Irey, R. K., McCaulley, M. H., "Self-Paced Instruction and College Student Personalities," Engineering Education, pp. 435-440, Mar., 1973.

15. Thorne, A., Harrison, G., Portraits of Type, An MBTI Research Compendium, Consulting Psychologists Press, Inc., Palo Alto, CA.

16. Trevistan, M.S., et. al., "Developing and Assessing Statewide Competencies for Engineering Design,” J. of Eng. Education, Vol. 87, No. 2, pg. 185-195, April, 1998.

17. Trevistan, M.S., et. al., "Designing Sound Scoring Criteria for Assessing Student Performance," J. of Eng. Education, Vol. 88, No. 1, pg. 79-87, Jan 1999.

18. Wilde, D.J., "Mathematical Resolution of MBTI Creativity Data into Personality Type Components", Design Theory and Methodology, ASME, DE-Vol. 53, pp37-43, 1993.

19. Wilde, D.J., "Using Team Preferences to Guide Design Team Composition," ASME Transactions (Design Engineering Technical Conference Proceedings), paper DETC/DTM-3980, New York, American Society of Mechanical Engineers, 1997.

20. Wilde, D.J.," Design Team Roles", ASME Transactions (Design Engineering Technical Conference Proceedings), paper DTM-99 003, Las Vegas, American Society of Mechanical Engineers, 1999. 


\section{MARTIN BOWE}

Martin Bowe is an Assistant Professor of Mechanical Engineering at the U.S. Air Force Academy. He received his B.S. in Mechanical Engineering from the U.S. Air Force Academy and his M.S. in Industrial and Systems Engineering from The Ohio State University. He is currently a Captain on active duty in the Air Force with a career specialization in Acquisition Program Management and Project Engineering.

\section{DAN JENSEN}

Dan Jensen is an Associate Professor of Engineering Mechanics at the U.S. Air Force Academy. He received his B.S., M.S. and Ph.D. from the Univ. of Colorado at Boulder. He has worked for Texas Instruments., Lockheed Martin, NASA, Univ. of the Pacific, Lawrence Berkeley National Lab and MacNeal-Schwendler Corp. Currently he teaches and performs research in the areas of design and analysis.

\section{JOHN FELAND}

John Feland is an Instructor of Mechanical Engineering at the U.S. Air Force Academy. He received his S.B. in Mechanical Engineering from the Massachusetts Institute of Technology and his M.S. in Mechanical Engineering from Stanford University. He is currently a Captain on active duty in the Air Force pursuing academic research with the Center for Design Research at Stanford University regarding the development of large-scale defense projects.

\section{BRIAN P. SELF}

Brian Self is an Assistant Professor of Mechanical Engineering at the U.S. Air Force Academy. He received his B.S. and M.S. in Engineering Mechanics from Virginia Tech and his Ph.D. in Bioengineering at the University of Utah. He has four years of experience with the Air Force Research Laboratory. Areas of research include impact injury mechanisms, sports biomechanics, and aerospace physiology. 


\section{APPENDIX 1 - 6-HATS TYPE DETERMINATION INSTRUMENT}

\section{Microsoft Excel - hat_survey.xls}

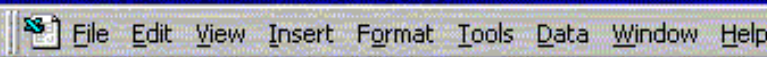

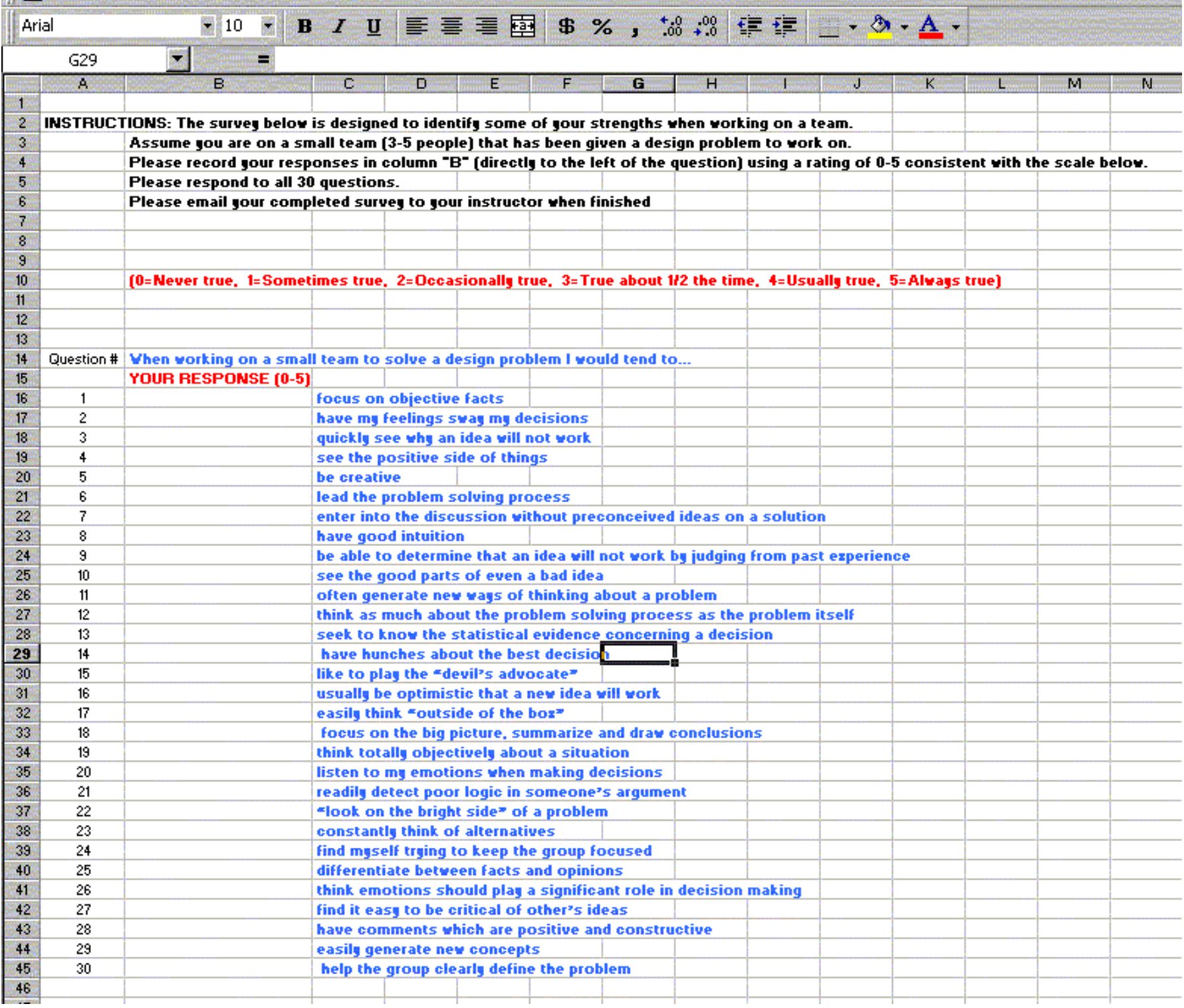




\section{APPENDIX 2 - TEAM EFFECTIVENESS SURVEY}

Name

Team Name

Current Grade

Course

Section

Please rate your team on the 13 statements listed below.

Use the following scale:

+2=Very True; +1=Mostly True; $\quad 0=$ Neutral; -1=Mostly Un-True; $\quad-2=$ =Very Un-True

If a statement is not applicable or if you have no opinion, please rate that statement as "NA" (for not applicable)

\begin{tabular}{|c|c|c|}
\hline $\begin{array}{l}\text { Statement } \\
\text { Number }\end{array}$ & Statement & $\begin{array}{l}\text { Rating (from }+2 \text { to }- \\
2 \text { using scale above) }\end{array}$ \\
\hline 1 & Our team is very creative & \\
\hline 2 & Our team has a lot of conflict & \\
\hline 3 & Our team has a clear leader & \\
\hline 4 & Our team is productive and effective & \\
\hline 5 & Our team resolves conflict well & \\
\hline 6 & Our teams sees the potential in new ideas & \\
\hline 7 & Our team approaches problem solving logically & \\
\hline 8 & Our team procrastinates & \\
\hline 9 & Our team sees when a new idea will not work & \\
\hline 10 & $\begin{array}{l}\text { Our team uses intuition, hunches and feeling to aid our } \\
\text { problem solving }\end{array}$ & \\
\hline 11 & $\begin{array}{l}\text { Our team considers the full range of options before making a } \\
\text { decision }\end{array}$ & \\
\hline 12 & Our team's members due their fair share of the work & \\
\hline 13 & I enjoy working on this team & \\
\hline 14 & Our team makes good decisions & \\
\hline 15 & Our team is good at creating alternative solutions to problems & \\
\hline
\end{tabular}




\section{APPENDIX 3 -- PERSONAL GROUP INTERACTION STYLES}

Name

Team Name

Course

Section

Please read through the 6 personal group interaction styles summarized in the matrix below. Then number the 6 styles from 1-6 based on your opinion of how you predominately function in problem solving groups (1 being your most dominant style, \#2 being second... \#6 being your least dominant style). Mark your ranking directly in the matrix below in the blank for "STYLE \#__ RATING"

\begin{tabular}{|c|c|}
\hline $\begin{array}{l}\text { STYLE \# } 1 \\
\text { I focus on objective facts. } \\
\text { I enter into a discussion without preconceived } \\
\text { ideas on a solution } \\
\text { I seek to know that facts of a situation } \\
\text { I seek to know the statistical evidence concerning } \\
\text { a decision } \\
\text { I try to think totally objectively about a situation } \\
\text { I seek to differentiate between facts and opinions } \\
\text { I am more interested in facts than opinions } \\
\text { STYLE \# } 1 \text { RATING (1-6) }\end{array}$ & $\begin{array}{l}\text { STYLE \# } 4 \\
\text { My feelings sway my decisions } \\
\text { I have good intuition } \\
\text { I often have hunches about the best decision } \\
\text { My personal opinions play a significant role in my } \\
\text { decision making process } \\
\text { I listen to my emotions when making decisions } \\
\text { I am suspicious of other people's decision making } \\
\text { process } \\
\text { I think emotions should play a significant role in } \\
\text { decision making }\end{array}$ \\
\hline $\begin{array}{l}\text { STYLE \# } 2 \\
\text { I usually see the positive side of things } \\
\text { I can often see the good parts of even a bad idea } \\
\text { I am usually optimistic that a new idea will work } \\
\text { I tend to see the valuable contributions in } \\
\text { people's ideas } \\
\text { I believe that most new ideas have significant } \\
\text { value } \\
\text { I usually "look on the bright side" of a problem } \\
\text { My comments are usually positive and } \\
\text { constructive }\end{array}$ & $\begin{array}{l}\text { STYLE \#5 } \\
\text { I can quickly see why an idea will not work } \\
\text { I often can tell an idea will not work by judging from } \\
\text { past experience } \\
\text { I like to play the "devil's advocate" } \\
\text { I can usually see the pitfalls in an idea } \\
\text { I can readily detect poor logic in someone's argument } \\
\text { I find it easy to be critical of other's ideas } \\
\text { I am often pessimistic of others ideas } \\
\text { STYLE \# } 5 \text { RATING (1-6) }\end{array}$ \\
\hline $\begin{array}{l}\text { STYLE \# } 3 \\
\text { I am creative } \\
\text { VIII. I often generate new ways of thinking about a } \\
\text { problem } \\
\text { I easily think "outside of the box" } \\
\text { I am good at finding new approaches to solving a } \\
\text { problem } \\
\text { I am constantly thinking of alternatives } \\
\text { I am not likely to settle for the "status quo" } \\
\text { I can easily generate new concepts } \\
\text { STYLE \# } 3 \text { RATING (1-6) }\end{array}$ & $\begin{array}{l}\text { STYLE \# } 6 \\
\text { I like to lead the problem solving process } \\
\text { I tend to think as much about the problem solving } \\
\text { process as the problem itself } \\
\text { I focus on the big picture, summarize and draw } \\
\text { conclusions } \\
\text { I find myself trying to keep the group focused } \\
\text { I tend to try to optimize the group problem solving } \\
\text { process } \\
\text { I often help the group clearly define the problem } \\
\text { I often find myself orchestrating the group } \\
\text { STYLE \# } 6 \text { RATING (1-6) }\end{array}$ \\
\hline
\end{tabular}

The 6 interaction styles are adapted directly from the "6 Hats" work of Ed DeBono as reported in the book Six Thinking Hats, Ed DeBono, Little, Brown \& Co, 1985 